\title{
UNUSUAL FUNDOPOSTERIOR RUPTURE OF SCARRED UTERUS IN THIRD TRIMESTER OF PREGNANCY
}

Vijayalakshmi B ${ }^{1}$, Sangamesh Mathapati

\section{HOW TO CITE THIS ARTICLE:}

Vijayalakshmi B, Sangamesh Mathapati. "Unusual Fundoposterior Rupture of Scarred Uterus in Third Trimester of Pregnancy". Journal of Evolution of Medical and Dental Sciences 2015; Vol. 4, Issue 22, March 16; Page: 39163919, DOI: $10.14260 /$ jemds/2015/564

INTRODUCTION: Uterine rupture is a rare but serious catastrophe in obstetrical practice which is associated with high maternal and neonatal mortality. ${ }^{1}$ Survivors are often impaired with reproductive function that results from surgical management which predisposes them to marital disharmony and psychological trauma. ${ }^{2}$ Apart from this anemia, septicemia, obstetric fistula, which makes the recovery process prolonged and turbulent one.

Uterine rupture is tearing of the uterine wall during pregnancy or delivery. It is divided into two main categories complete and incomplete. ${ }^{3}$

Complete- when it involves myometrium and serosa, incomplete- when only myometrium is involved with intact serosa. Although there is decline in incidence of uterine rupture in various studies but when it occurs it has a hazardous impact on mother and foetus.

Surgical management depends on the type, site of rupture, parity, number of living issues and intra operative assessment of rupture. The surgical management may be:

1. Repair alone.

2. Repair with permanent sterilization.

3. Subtotal hysterectomy.

4. Total hysterectomy.

With the availability of advances in treatment of shock, better anesthesiology, improved operative measures, control of infection, blood transfusion facilities with improved antenatal and intra partum care both maternal \& foetal, mortality and morbidity have reduced. Here by we present a case of uterine rupture in third trimester pregnancy.

KEYWORDS: Uterine rupture, Scarred uterus, Haemoperitonium, Unscarred uterus, Fundoposterior ruptures.

CASE REPORT: A 25 year old $\mathrm{G}_{2} \mathrm{P}_{1} \mathrm{~L}_{0}$ with 8 months of amenorrhea with pain abdomen with previous lower segment caesarean section was referred from a private hospital in Bellary with a scan report stating an Intrauterine fetal demise with sonographic age of 32 weeks 0 days with:

- Type III placenta previa.

- Chorioangioma (101x80x60 mm).

- Gross maternal ascitis (volume > 2 liters).

On general examination patient had severe pallor, pulse rate of 110 beats per minute, and blood pressure of 120/80 mm of Hg. On per abdomen examination- Abdomen was distended with diffuse tenderness. The size and contour of uterus could not be appreciated. Fetal parts easily felt. Per speculum examination revealed no bleeding. Per vaginal examination cervix uneffaced, os closed. Paracentesis was positive for blood. 


\section{CASE REPORT}

Her hemoglobin was 7gm\%, Blood grouping and Rh typing -AB positive, BT- $2 \mathrm{~min}$, CT- 3min 52sec, PT-13min, APTT-35 min, INR1. 12.

After arranging adequate blood (4 points) patient was taken for emergency laporotomy. On exploration there was haemo peritoneum. The placenta was lying in the pelvis and fetus was in the abdominal cavity. A rupture was noted in the fundo posterior region which extended up to body of the uterus posteriorly. The anterior uterine wall was intact. After separating the bladder from lower uterine segment subtotal hysterectomy was done. Drain kept and abdomen closed in layers. Three points of blood was transfused per operatively and 1 point post operatively. Drain removed on $3^{\text {rd }}$ post op day. Patient recovered well and discharged on $8^{\text {th }}$ post-operative day.

DISCUSSION: Rupture of gravid uterus is a life threatening obstetric problem in which the life of both mother and fetus are in danger. The incidence of ruptured uterus is $0.3 \%$ to $1.7 \%$ in women with scarred uterus and $0.03 \%$ to $0.08 \%$ among women with unscarred uterus ${ }^{4}$. The perinatal mortality between $74 \%$ and $94 \%$.

There are several risk factors for rupture uterus like multi parity 5 uterotonic drugs, placenta percreta $^{6}, \mathrm{CPD}$, mal position, mal presentation, internal podalic version, perforation of uterus during MTP, instrumental delivery, and scarred uterus following operations on uterus like caesarean section, myomectomy, utericuloplasty.

\section{Warning Signs of Rupture Uterus during Pregnancy:}

1. Frequent and strong uterine contractions occurring more than 5 times in every 10 minutes and/ or each contractions lasting for 60-90 sec or longer.

2. Tenderness in lower uterine segment.

3. Bandle's ring formation.

4. Vaginal bleeding.

Other signs which rapidly follow are tender abdomen, easily palpable fetal parts, absent fetal heart sounds. A silent rupture presents without any initial dramatic signs and symptoms except rise in maternal pulse rate, pallor, and after several hours if not diagnosed they may progress to hypotension and shock.

The reduction of prevalence of rupture requires antenatal identification of risk factors, reduction of unwanted pregnancies and decreasing high parity, easy access of obstetrics services including caesarian section and reduction in aberrant use of uterotonic drugs particularly during intra partum period.

Uterine rupture occurring in an unusual site in a scarred uterus is sometimes an unpredictable event. In our case the patient had a previous LSCS in a private hospital 8 years back for IUFD with? Placenta previa. If we analyze the present rupture there is possibility that the previous operating surgeon might have taken fundal incision during caesarian section due to technical reasons and it could be the cause for antenatal rupture of uterus.

CONCLUSION: Uterine rupture is a complication in obstetrics which is difficult to be predicted due to its unclear and plural etio pathogenesis. Despite its rare occurrence, an obstetrician should have this complication in mind especially if diagnosis is due to potential nonspecific signs and symptoms. 


\section{CASE REPORT}

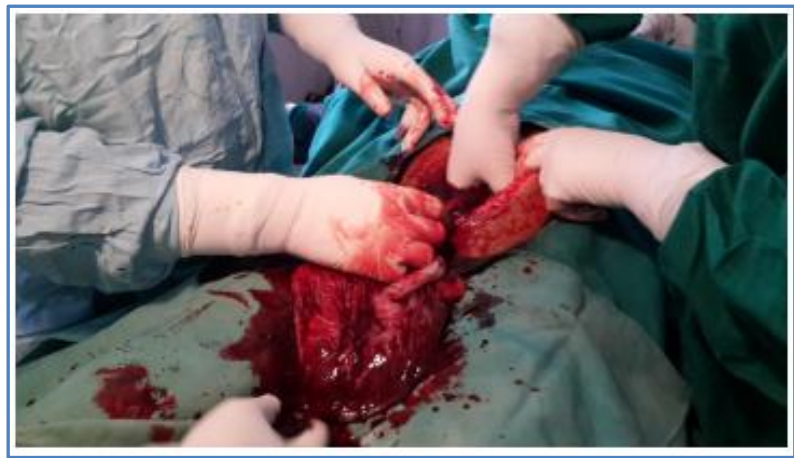

Fig. 1: Placenta lying in Abdominal cavity

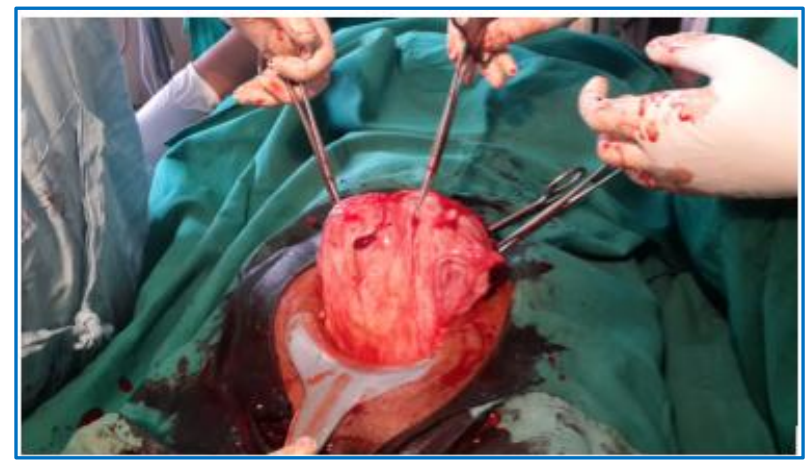

Fig. 3: Intact anterior wall

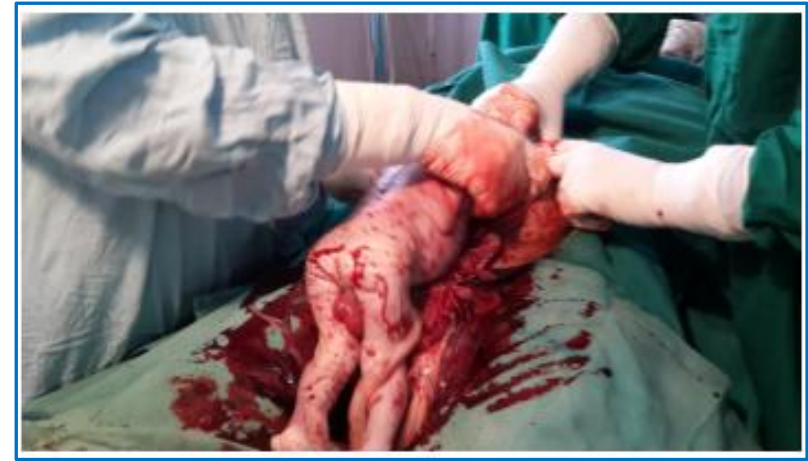

Fig. 2: Fetus retrieved from Abdominal cavity

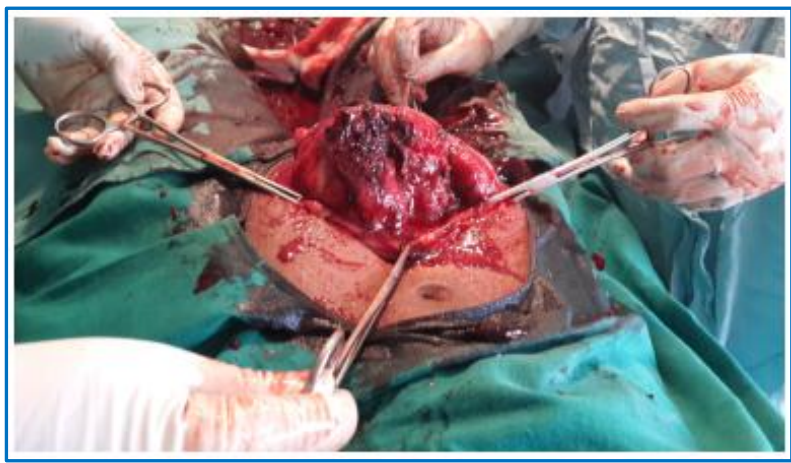

Fig. 4: Ruptured fundo posterior part

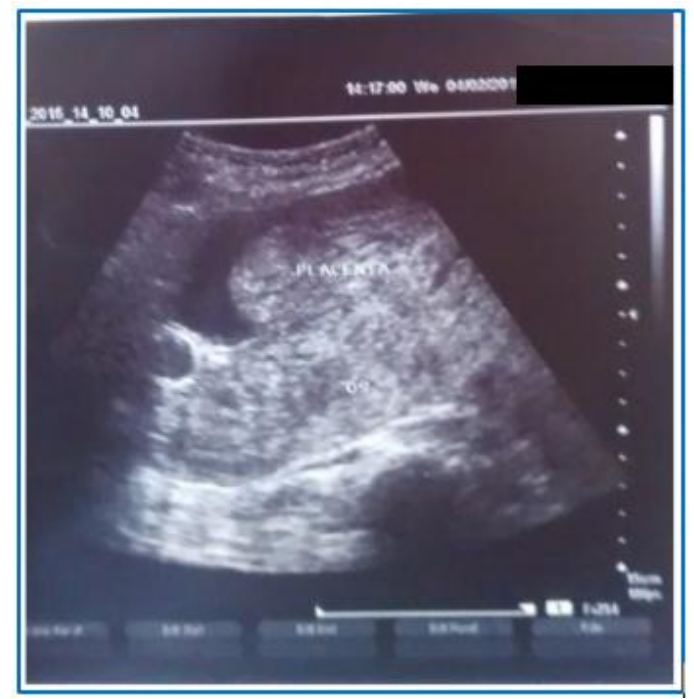

Fig. 6: USG showing placenta previa

Fig. 5: Post hysterectomy specimen 


\section{CASE REPORT}

\section{REFERENCES:}

1. Ezechi OC, Mabayoje P, Obiesie LO, Ruptured uterus in south Western Nigeria: a reappraisal, Singapore Med J 2004; 45: 113-6.

2. Gessessew A, Melese MM. Ruptured uterus eight year retrospective analysis of causes and management out come in Adigrat hospital, Tigray Region, Ethiopia, Ethiop J Health Dev 2002; 16: 241-5.

3. WHO systematic review of maternal mortality and morbidity: The prevlence of uterine rupture. BJOG: An International Journal of Obstetrics and Gynaecology. 2005, 112, 1221-1228.

4. Hamilton EF, Bujold E, Mc Narma H, Gauthier R, Platt AW. Dystocia among women with symptomatic uterine rupture. Am J Obstet Gynecol. 2001, 184, 620-624.

5. Neilson JP, Lavender T, Quenby S, Wray S. Obstructed labour. Br Med Bull 2003, 67, 191-204.

6. Topuz S. Spontaneous uterine rupture at an unusual site due to placenta percreta in a 21 week twin pregnancy with previous caesarean section. Clin Exp Obstet Gynecol. 2004, 31, 239-241.

\section{AUTHORS:}

1. Vijayalakshmi B.

2. Sangamesh Mathapati

\section{PARTICULARS OF CONTRIBUTORS:}

1. Associate Professor, Department of Obstetrics \& Gynaecology, VIMS, Bellary.

2. Senior Resident, Department of Obstetrics \& Gynaecology, VIMS, Bellary.

FINANCIAL OR OTHER

COMPETING INTERESTS: None

\section{NAME ADDRESS EMAIL ID OF THE} CORRESPONDING AUTHOR:

Dr. Vijayalakshmi. B, House No: 10/2, Ward No: 19, Behind Govt. School, Patel Nagar, Bellary. E-mail: vijaya.b.yadav72@gmail.com

Date of Submission: 09/02/2015.

Date of Peer Review: 10/02/2015.

Date of Acceptance: 04/03/2015.

Date of Publishing: 16/03/2015. 